\section{Getting connected to the White House Conference through the ACRL Legislative Network}

\author{
by Hiram L. Davis
}

\author{
Chair, ACRL Government Relations \\ Committee, and \\ Member, ACRL Task Force on WHCLIS
}

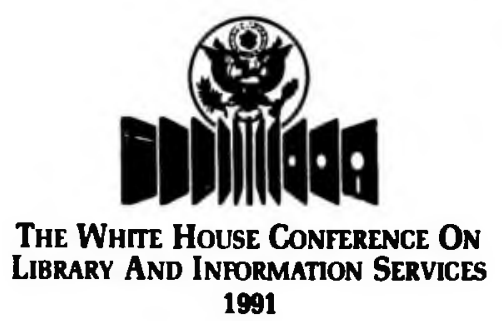

1991
A collective voice from the academic library community is imperative if we are to respond proactively to the forthcoming White House Conference on Libraries and Information Services (WHCLIS) and to the broad range of governmental issues confronting academic libraries. A coherent plan of action from the Association will be essential in implementing Conference recommendations for further improvement of library and information services aimed at increasing productivity, expanding literacy, and strengthening democracy, as we approach the 21 st century.

\section{Impetus for a network}

The ACRL Strategic Planning Document provides the platform for a national legislative network: Goal III. To promote and speak for the interests of academic and research librarianship; Subgoal B. To monitor and speak out on government and private sector activities likely to affect academic and research librarianship, including legislation and fiscal and political support at all levels; Objective 1. Establish ACRL as the association with the authority to speak for the academic library profession on issues of importance to higher education and academic libraries; Objective 2. Strengthen membership efforts to affect and influence government and private sector activities, including legislation, funding, and quality higher education. Under this rubric ACRL charged its Government Relations Committee (GRC): "To take a direct and active role in formulating objectives and in planning and coordinating support for legislative action at the national level which may affect the welfare of academic and research libraries."

\section{Developing the network}

One of the challenges faced by the GRC was to identify an appropriate model or structure to mobilize the academic community into an effective and responsive network for the profession. It was decided that ACRL, through its $40+$ state-wide

(Washington Hotline con't from previous page)

legislation to provide a more direct voice for the research and education communities the NREN is intended to serve. He also said that libraries should be included.

ALA ACTIONS. ALA's statement, submitted for both hearing records, built on the January 16 ALA Council resolution on the NREN and the January 25 Partnership for the NREN policy framework. ALA called for eligibility for libraries, a voice for involved constituencies in network policy, high-capacity network connections with all 50 states, education and training funds, and direct connections to the NREN for at least 200 key libraries and library organizations and dial-up access for multitype libraries within each state. Prime candidates suggested for direct connection (some of which are already connected to the current Internet) were national libraries, regional depository libraries, state library agencies, library networks, libraries in geographic areas with a scarcity of NREN connections, and libraries with specialized or unique resources. 
Table 1: ACRL Government Relations Committee

Committee Chapter Liaisons (1990/91)

$\begin{array}{ll}\text { Region } 1 & \text { Henry Mandelsohn, State University of New York, (518) 442-3698 } \\ \text { Cheryl Naslund, Institute for Development Anthropology, (607) 785-0430 }\end{array}$

Region 2 Patricia Wand, American University, (202) 885-3237

Region 3 Berna Heyman, College of William and Mary, (804) 221-3059

Region 4 Charles Beard, West Georgia College, (404) 832-9458

Region 5 Willie Hardin, University of Central Arkansas, (501) 450-3129

Region $6 \quad$ Evelyn Brass, University of Houston Libraries, (713) 749-4762

Kerry Keck, Rice University, (713) 523-2417

Region 7 Hiram Davis, Michigan State University, (517) 355-2341

Linda Kopecky, University of Illinois at Chicago, (312) 996-2738

Wendy Lounge, University of Michigan, (313) 763-1539

Connie Stoner, Shawnee State University, (614) 355-2462

Region 8 Susan Brant, Nicolet Area Technical College, (715) 369-4439

Region 10 Carol Burroughs-Hammond, Arizona State University-West, (602) 543-8504

Region 12 Anthony Angiletta, Stanford University Libraries, (415) 723-1813

Joyce Toscan, University of Southern California, (213) 740-2931

chapters and state-affiliated associations, already has in place the infrastructure to provide a regional and nationwide academic library network. Each of the sixteen GRC members are to serve as liaison to the ACRL Chapters in the geographical regions they represent. (These regions and GRC member liaisons are listed in tables 1 and 2; for more information should contact regional GRC members.) The ACRL Chapters have agreed to support the legislative network. Through Chapters Council and their newsletter Chapter Topics, each Chapter has been asked to assign an individual or a committee responsibility for legislative issues at the federal level. Members of GRC are to take a proactive role in establishing the liaison relationship and encouraging the Chapters to address legislative issues of importance to the profession. The GRC recently developed a set of guidelines for committee members, outlining liaisons' and Chapters' responsibilities and related legislative activities.

\section{The network and WHCLIS}

ACRL's Legislative Network could not have come into existence at a more propitious time. The forthcoming White House Conference will provide an excellent test of the effectiveness of the Network. The link between members of GRC and the ACRL Chapters provides a system for distributing information on each state's WHCLIS activities. Further, it provides a mechanism for coordinating grassroots responses from the academic library community. Given the relatively small number of academic librarians who are delegates to the Conference, the Network can facilitate and broaden participation. The Conference will provide the framework for shaping the future role of the Federal Government with respect to supporting libraries and information services. The Network will be an important element in alerting members of ACRL to the critical issues regarding federal legislation that may be necessary to advance Conference recommendations, and in mobilizing the academic community to provide support for legislative action. The success of WHCLIS and the ACRL Legislative Network are inextricably linked; it is essential that academic librarians be connected to both. 


\section{ACRL Government Relations Committee Legislative Network Regional Liaisons}

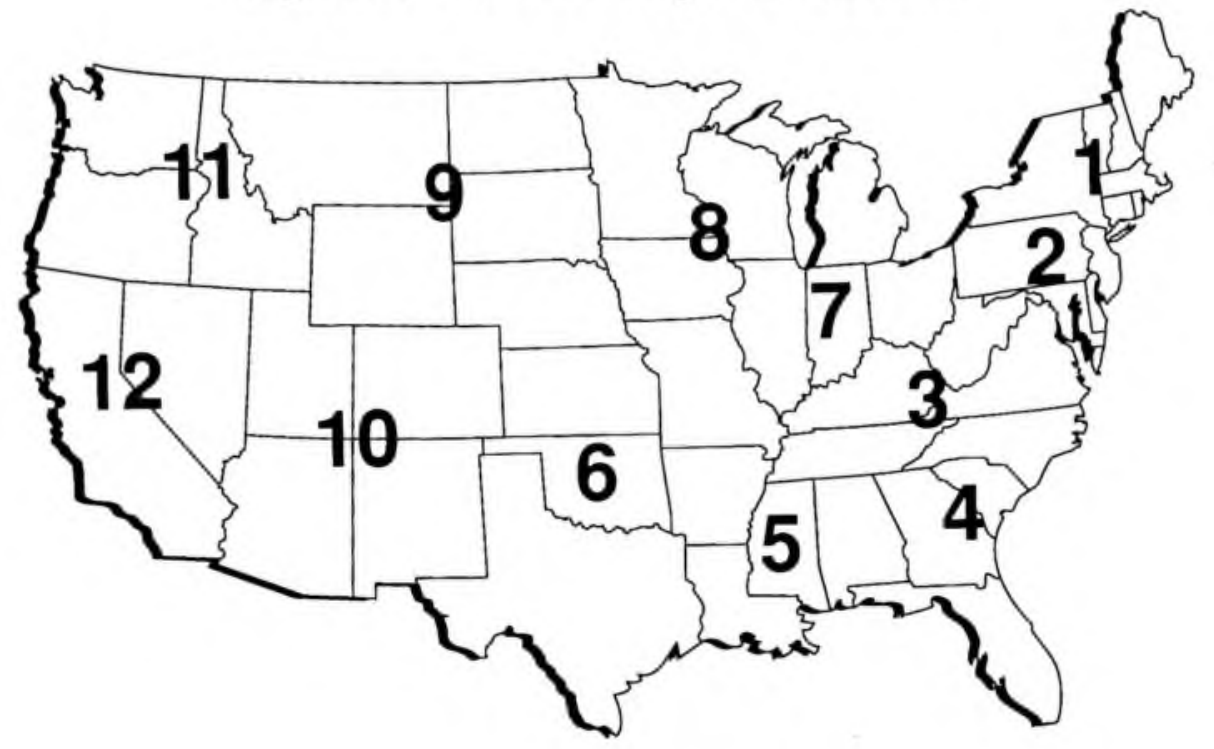

Table 2: ACRL Legislative Network Map Key-Regions: States

1. CT, MA, NH, RI, VT, NY, ME

Canada: New Brunswick, New Found-

land, Nova Scotia, Quebec, Eastern

Ontario

2. DE, MD, NJ, PA

3. KY, TN, VA, WV

4. FL, GA, NC, SC (no chapter),

Puerto Rico, Virgin Islands

5. AL, AR, LA, MS

6. $\mathrm{KS}, \mathrm{MO}, \mathrm{OK}, \mathrm{TX}$
7. IL, IN, MI, OH,

Canada: Central Ontario

8. IA, MN, NE, WI

Canada: Manitoba, Western Ontario

9. $\mathrm{MT}, \mathrm{ND}, \mathrm{SD}, \mathrm{WY}$ (no chapter)

10. AZ, CO, NM, UT, Mexico

11. AK (no chapter), HI, ID, OR, WA

Canada: British Columbia

Guam, Trust Territories, Samoa

12. $\mathrm{CA}, \mathrm{NV}$ 